\title{
$\beta$-Microseminoprotein in human spermatozoa and its potential role in male fertility
}

\author{
N Anahí Franchi, Conrado Avendaño, Rosa I Molina ${ }^{1}$, Andrea D Tissera ${ }^{1}$, Cristina A Maldonado ${ }^{2}$, \\ Sergio Oehninger ${ }^{3}$ and Carlos E Coronel \\ Laboratorio de Bioquímica y Biología Reproductiva, Instituto de Ciencia y Tecnología de Alimentos, Facultad de \\ Ciencias Exactas, Físicas y Naturales, Universidad Nacional de Córdoba, Córdoba 5000, Argentina, ' Laboratorio de \\ Andrología y Reproducción (LAR), Córdoba 5000, Argentina, ${ }^{2}$ Centro de Microscopía Electrónica, Facultad de \\ Ciencias Médicas, Universidad Nacional de Córdoba, Córdoba 5000, Argentina and ${ }^{3}$ Department of Obstetrics \\ and Gynecology, Eastern Virginia Medical School, The Jones Institute for Reproductive Medicine, Norfolk, \\ Virginia 23507, USA
}

Correspondence should be addressed to N A Franchi; Email: franchna@evms.edu

\begin{abstract}
$\beta$-Microseminoprotein (MSMB) is one of the most abundant proteins in human seminal plasma. The objectives of this study were: (1) to purify MSMB from seminal plasma (SP) and generate antibodies against the pure protein; (2) to investigate the interaction of MSMB with ejaculated spermatozoa and its possible effect on the spontaneous acrosome reaction (AR); and (3) to quantify MSMB content in SP and examine its relationship with the clinical sperm parameters. MSMB was purified from SP and its presence on the sperm surface was examined by indirect immunofluorescence using a specific polyclonal antibody. The effect of MSMB on the AR was evaluated using guinea pig epididymal spermatozoa as a model. MSMB quantification assay was performed with a two-site binding ELISA using two polyclonal antibodies against MSMB. MSMB was assessed in semen samples from fertile donors (controls) and subfertile patients according to World Health Organization criteria. MSMB was detected on the sperm surface and mainly localized to the acrosomal region of the head and neck. A significant spontaneous AR inhibition was observed when guinea pig epididymal spermatozoa were preincubated with MSMB. Finally, MSMB was significantly increased in subfertile patients when compared with fertile controls $(P<0.02)$. The association of MSMB to the sperm surface, the inhibitor effect on the spontaneous AR and the increased MSMB levels found in SP in subfertile men suggests a relationship between this protein and semen quality and a possible role in the process of fertilization.
\end{abstract}

Reproduction (2008) 136 157-166

\section{Introduction}

$\beta$-Microseminoprotein (MSMB), also called prostatic secretory protein 94 (PSP94), is one of the most abundant proteins in the secretions produced by the human prostate. Originally, MSMB was isolated from human seminal plasma (SP) (Akiyama et al. 1985) but has subsequently been identified in several different species, including baboon (Xuan et al. 1997), rhesus monkey (Nolet et al. 1991), rat (Fernlund et al. 1996), pig (Fernlund et al. 1994), and mouse (Xuan et al. 1999). MSMB is a cysteine-rich nonglycosylated protein with an apparent molecular mass of $15 \mathrm{kDa}$ as determined by SDS-PAGE. The human gene for MSMB has been cloned and mapped to chromosome 10 (q11.2) and there are three glucocorticoid response elements and one estrogen response element in the promoter region of the first intron. These findings suggest that the gene may be regulated by hormones (Nolet et al. 1991, Ochiai et al. 1995) as also reported in rat lateral prostate (Kwong et al. 2000). Although putative biological/clinical roles have been suggested, i.e., acting as an immunoglobulin binding factor (Kamada et al. 1998) and/or tumor marker for prostate cancer (Sakai et al. 1999), the biological function of MSMB in the male or female reproductive tract is still unknown.

Semen evaluation for human male infertility and assisted reproduction relies on conventional measures of light microscopic evaluation of sperm count, morphology, and motility (WHO 1999), and provides useful, yet somewhat limited, clinical information in couples seeking infertility treatment. The semen analysis, upon which the diagnosis of male factor infertility is based, is highly subjective (Amann 1989, Coetzee et al. 1999). Few objective methods for infertility diagnostic and fertility prediction are currently available, some of them based on the detection of DNA damage (Henkel 2007). The correlation between clinical semen parameters and fertility is moderate to low (Guzick et al. 2001). For instance, sperm with intrinsic defects may appear morphologically normal upon light microscopic evaluation (Nikolettos et al. 1999) and there is substantial 
inter-laboratory variability in both subjective and automated morphological semen analyses (Neuwinger et al. 1990, Jorgensen et al. 1997, Coetzee et al. 1999).

Therefore, additional objective techniques for semen evaluation, not based on conventional measures of semen parameters, are sought (Amann 1989, Douglas-Hamilton 1995, Krause 1995). In this respect, the characterization of semen proteins interacting with the spermatozoa may be critical in order to understand their relationship with semen quality and sperm functional competence. The aims of the present study were: (1) to purify MSMB protein and to develop specific antibodies against MSMB; (2) to investigate whether MSMB binds to the human sperm surface on a specific manner and to characterize its localization; (3) to generate and characterize an antibody system to develop a two-site binding ELISA for MSMB quantification; and (4) to analyze whether the quantity of the antigenic MSMB is related to fertility. For these purposes, we compared the level of MSMB in SP from proved fertile men and from subfertile patients.

\section{Results}

\section{Protein purification and antibodies characterization}

MSMB was purified from human SP using salt precipitation and a combination of chromatographic methods. After the first step of solid ammonium sulfate precipitation (35\% saturation), the protein was found in the supernatant. This material was brought to $70 \%$ saturation, and the protein was present in the precipitate, which was used as the starting material in the following chromatographic steps. Two rounds of gel filtration chromatography were used and the fractions containing MSMB were pooled and loaded onto an anion interchange column, where the elution was carried out applying a continuous $\mathrm{NaCl}$ gradient from 0 to $0.5 \mathrm{M}$ in buffer $25 \mathrm{mM}$ Tris- $\mathrm{HCl}$ ( $\mathrm{pH}$ 7.6). In order to achieve homogeneity, the fractions containing MSMB were subjected to a high performance liquid chromatography (HPLC) step in an Ultraspherogel Sec 2000 column $(0.75 \times 30 \mathrm{~cm})$. MSMB purity was assessed by SDS-PAGE (Fig. 1A).

Polyclonal antibodies against MSMB were generated in rabbit and rat by inoculation of pure MSMB as described in the Materials and Methods section. In order to determine the antibodies specificity, Western immunoblot analysis of human SP proteins was performed using rabbit and rat anti-MSMB antiserum as a primary antibody. Among the protein components of $\mathrm{SP}$, rabbit antiserum reacted only with a $15 \mathrm{kDa}$ band, corresponding to MSMB protein, showing the monospecificity of the anti-MSMB antibody (Fig. 1B and C). A similar result was obtained with the rat anti-MSMB. Thereafter, we used the rabbit anti-MSMB antiserum for the immunodetection of MSMB on sperm surface. $A$ fraction of rabbit MSMB antiserum was used to isolate
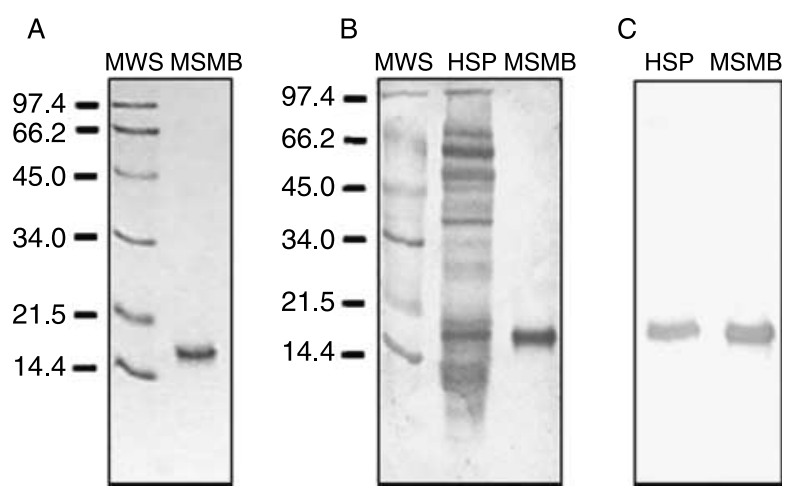

Figure $1 \mathrm{MSMB}$ protein purified from human seminal plasma and MSMB antibody specificity. (A) MSMB purified to homogeneity. Seminal plasma proteins were subjected to SDS-PAGE followed by immunoblotting with rabbit anti-MSMB antibody. (B) Coomassie Brilliant Blue staining. (C) Immunoblotting with rabbit anti-MSMB. MWS, molecular weight standards; HSP, human seminal plasma proteins; MSMB, pure MSMB protein.

the IgG fraction by affinity chromatography in a protein A-Sepharose column. Purified rabbit IgG were used as capture antibody in the ELISA assay. Rat anti-MSMB was used as a detection antibody.

\section{MSMB immunolocalization on sperm surface}

To evaluate the presence of MSMB binding sites on the sperm surface, ejaculated spermatozoa were examined by indirect immunofluorescence (IIF) using the rabbit monospecific polyclonal antibody anti-MSMB. Freshly ejaculated sperm showed different fluorescence patterns. As shown in Fig. 2A and B, in most of the sperm cells the immunostaining was localized to the anterior region of the head, indicating $\mathrm{MSMB}$ binding sites on the acrosomal region. In a few cases, staining was localized to the equatorial region and neck (Fig. 2C). No immunofluorescence was observed when rabbit nonimmune serum was used or the first antibody was avoided.

Samples from the same set of experiments were submitted to ultrastructural immunocytochemistry using protein-A colloidal gold complex and then examined by electron microscopy. Different spermatozoa fixed immediately after collection showed gold labeling corresponding to $\mathrm{MSMB}$ in the plasma membrane on the sperm head (Fig. 3). These results confirmed MSMB localization observed by immunofluorescence.

Since MSMB has specific binding sites on the sperm surface, we investigated whether MSMB could affect some of the processes that sperm undergo after the ejaculation and before fertilizing the egg. While the ejaculated spermatozoa have MSMB already bound in their surface, we examined an animal model in order to obtain epididymal spermatozoa to assay the binding of exogenously added MSMB. 


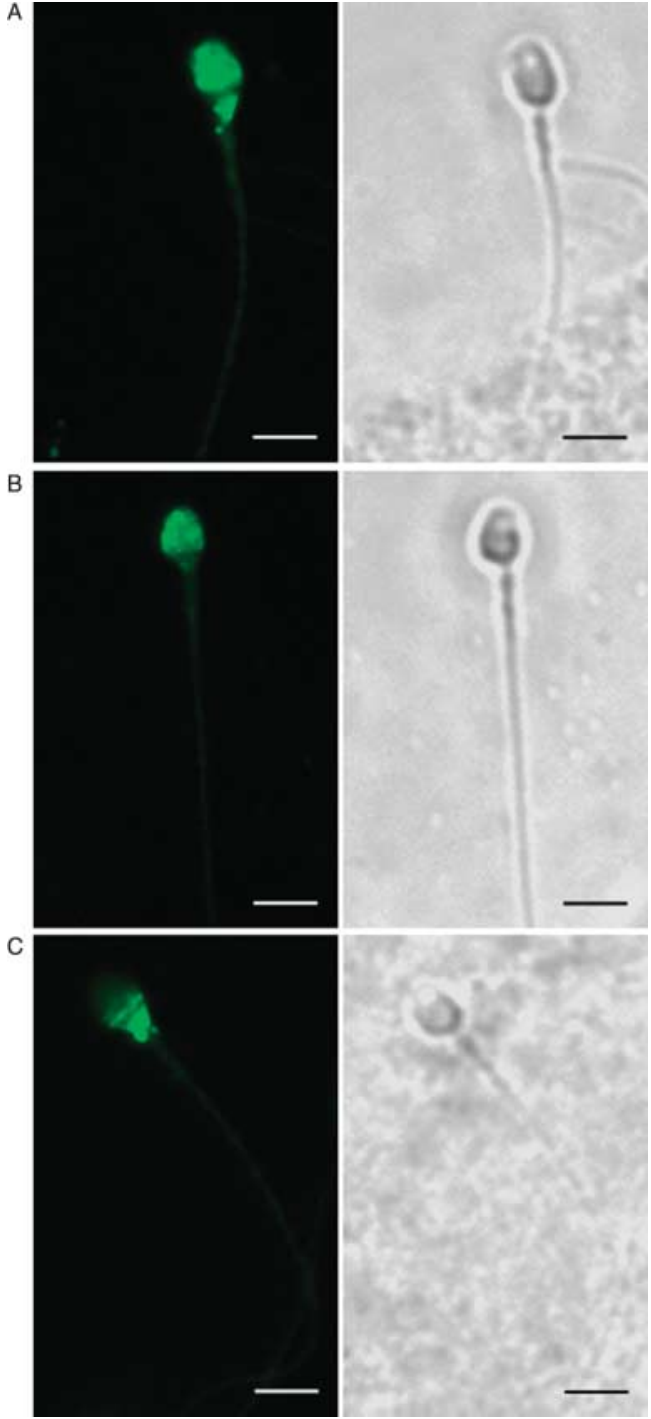

Figure 2 Immunodetection of MSMB in freshly ejaculated human spermatozoa exposed to anti-MSMB antibody and FITC-conjugated secondary antibody. Immunofluorescent patterns of MSMB localization (left) and the corresponding phase contrast images (right). A bright fluorescence localized in the acrosomal region of the (A) head and (B) neck was the prevalent pattern observed in the immunoflorescent images. (C) Some of the cells showed immunostained on the ecuatorial region and neck. Original magnification $630 \times$. The scale bar represents $5 \mu \mathrm{m}$.

\section{MSMB immunolocalization on guinea pig sperm and effect on the acrosome reaction (AR)}

Epididymal sperm were obtained from the caudal region of guinea pig epididymis. Sperm were washed, incubated 90 min in the presence of MSMB, and subjected to IIF using anti-MSMB antibody. We found that MSMB binds to guinea pig sperm on the acrosomal region of the head (Fig. 4). Based on this observation, we evaluated the possible effect of MSMB on the spontaneous AR. The percentage of acrosome-reacted sperm was evaluated in sperm incubated in the absence or presence
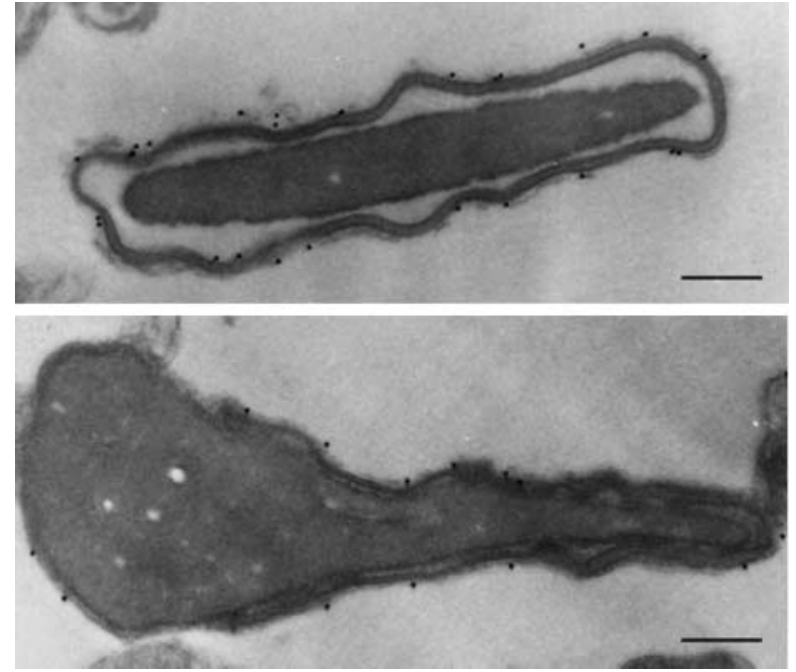

Figure 3 Ultrastructural analysis of MSMB localization in human spermatozoa by immunoelectron microscopy. Sections of freshly ejaculated human spermatozoa were fixed immediately after collection and incubated with anti-MSMB antiserum followed by colloidal goldlabeled protein. Sections through the sperm head depicting intact plasma membrane and showing colloidal gold particles. The scale bar represents $0.5 \mu \mathrm{m}$.

of $0.5 \mathrm{mg} / \mathrm{ml} \mathrm{MSMB}$ during 90 or $180 \mathrm{~min}$. During this time, the sperm viability was $\geq 90 \%$.

After $90 \mathrm{~min}$ of incubation, $11.6 \pm 0.5 \%$ of sperm experimented spontaneous AR in the absence of MSMB compared with $5.24 \pm 0.4 \%$ in the presence of the protein. After $180 \mathrm{~min}, 16.0 \pm 1.0 \%$ were reacted compared with $9.6 \pm 1.2 \%$ in the presence of MSMB (Fig. 5). These results
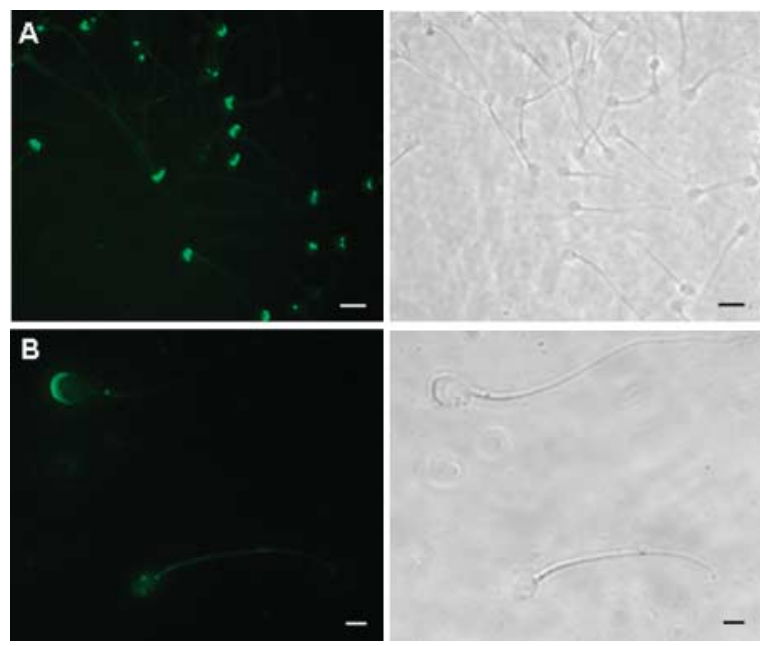

Figure 4 Immunolocalization of MSMB on guinea pig epididymal spermatozoa. (A) Indirect immunofluorescence using anti-MSMB antibody (left) and their corresponding phase contrast (right) showing MSMB binding to the acrosomal region; original magnification: $200 \times$, scale bar represents $10 \mu \mathrm{m}$. (B) at higher magnification is shown, MSMB presence on an intact sperm (upper), while the fluorescence is absent in the acrosome-reacted sperm (lower). Original magnification: $630 \times$, scale bar represents $5 \mu \mathrm{m}$. 


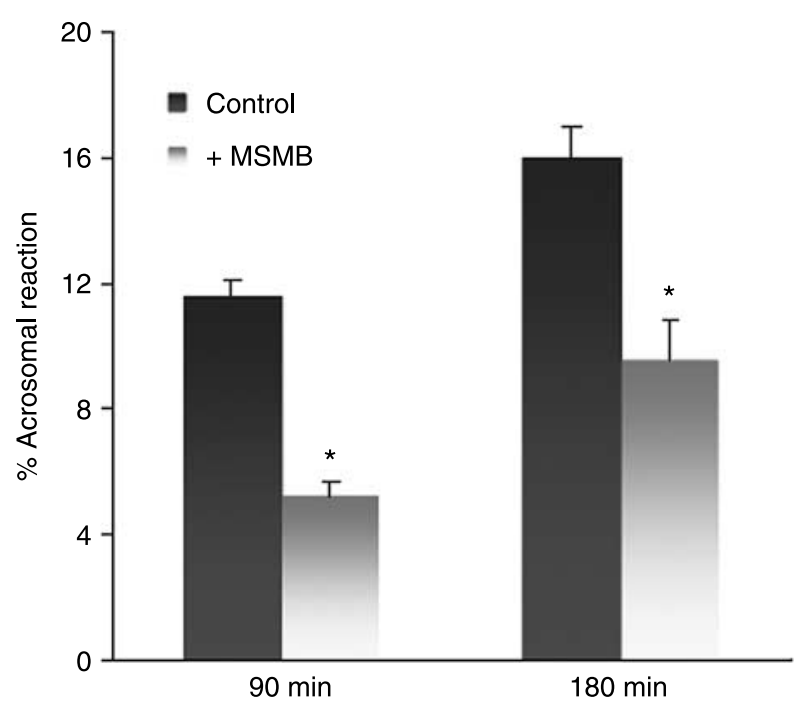

Figure 5 Effect of MSMB on the spontaneous acrosomal reaction of guinea pig epididymal spermatozoa. Cells were fixed immediately $\left(t_{0}\right)$ or after the indicated incubation times in the presence or absence of $0.5 \mathrm{mg} / \mathrm{ml} \mathrm{MSMB}$. Results are expressed as the acrosome reaction percentage after subtracting the percentage of acrosomal reaction at $t_{0}$. Data represent mean \pm s.D. of three independent experiments. ${ }^{*} P<0.05$ versus control.

indicate that the presence of MSMB in the incubation medium caused a significant inhibition of the $A R$ of approximately $55 \%$ after $90 \mathrm{~min}$ and $40 \%$ after $180 \mathrm{~min}$ of incubation $(P<0.05)$.

\section{ELISA evaluation of SP MSMB}

In order to evaluate the MSMB concentration in SP, a two-site binding ELISA for the detection of MSMB was developed using a combination of the two antibodies as indicated in Materials and Methods section. Purified rabbit IgG anti-MSMB was obtained and used as capture antibody. This antibody was linked to the wells of the ELISA plate surface enabling to secure free antigen. The second anti-MSMB antiserum was developed in rat and was used as detection antibody to recognize the captured antigen, and the alkaline phosphatase-linked anti-detector antibody recognizes bound detection antibodies. Finally, AP substrate was used to generate a quantifiable color signal. The standard curve was obtained using serial dilutions of pure MSMB protein. The detection limit for the assay was $4.30 \mathrm{ng} / \mathrm{ml}$, and the within-assay and between-assay coefficients of variation were 7.21 and $15.05 \%$ respectively. SP samples in appropriate dilution were used to secure MSMB values within the lineal range. MSMB concentration was expressed relative to the total protein concentration.

\section{Evaluation of the relationship between clinical semen analysis and MSMB levels in SP}

A total of 68 semen samples were analyzed. The MSMB SP levels were analyzed by double-site ELISA in SP samples from 38 oligoasthenoteratozoospermic (OAT) patients, 7 asthenozoospermic (AS), and 17 teratozoospermic. In addition, the teratozoospermic group was divided in two subgroups according to the pathology intensity: severe teratozoospermic (ST, eight samples) and moderate teratozoospermic (MT, nine samples). Six proved fertile donors were analyzed as a control group. The semen parameters of the five groups of subjects analyzed for MSMB concentration in SP are summarized in Table 1. MSMB concentration range was $0.579-10.751 \mathrm{mg} / \mathrm{ml}$ for the whole population. The total protein concentration ranged from 14.603 to $67.201 \mathrm{mg} / \mathrm{ml}$ and was not significantly different between groups according to ANOVA analysis. In order to compare the MSMB levels between different subpopulations, MSMB concentration was expressed relative to the total SP protein concentration. The MSMB levels were represented as mean values \pm S.E.M. in Fig. 6, showing a significantly $(P<0.02)$ increased value in OAT $(0.101 \pm 0.012)$, AS $(0.132 \pm 0.028)$, and ST $(0.133 \pm 0.024)$ patients compared with fertile subjects $(0.067 \pm 0.008)$.

\section{Discussion}

In the present study, we are showing for the first time that MSMB, one of the major proteins present in human SP, has binding sites on the human sperm surface.

Semen derives from the mixing of sperm-rich epididymal fluid and secretions provided by the accessory sex glands, i.e., mainly the seminal vesicles and the prostate. The biological functions of most proteins in these secretions are still unknown, even though some of them are very abundant in SP. Prostate-specific antigen, prostate-secreted acid phosphatase, and MSMB are the proteins secreted at highest levels in the prostate fluid.

Table 1 Median semen parameters according to groups.

\begin{tabular}{|c|c|c|c|c|c|}
\hline Parameter & $\mathbf{F}(n=6)$ & OAT $(n=38)$ & $\mathbf{S T}(n=8)$ & $\mathbf{M T}(n=9)$ & AS $(n=7)$ \\
\hline Sperm concentration $\left(\times 10^{6} / \mathrm{ml}\right)$ & $51.4 \pm 13.4$ & $1.0 \pm 1.4$ & $28.5 \pm 7.2$ & $38.4 \pm 7.6$ & $62.5 \pm 29.0$ \\
\hline Total motility (\%) & $61.0 \pm 15.1$ & $7.4 \pm 8.7$ & $56.9 \pm 8.0$ & $66.7 \pm 9.0$ & $33.6 \pm 13.4$ \\
\hline Normal forms (\%) & $16.8 \pm 5.8$ & $0.8 \pm 1.4$ & $2.9 \pm 1.0$ & $9.4 \pm 0.7$ & $16.3 \pm 3.1$ \\
\hline
\end{tabular}

Mean \pm s.D. F, fertile; OAT, oligoasthenoteratozoospermic; ST, severe teratozoospermic; MT, moderate teratozoospermic; AS, asthenozoospermic subjects. 


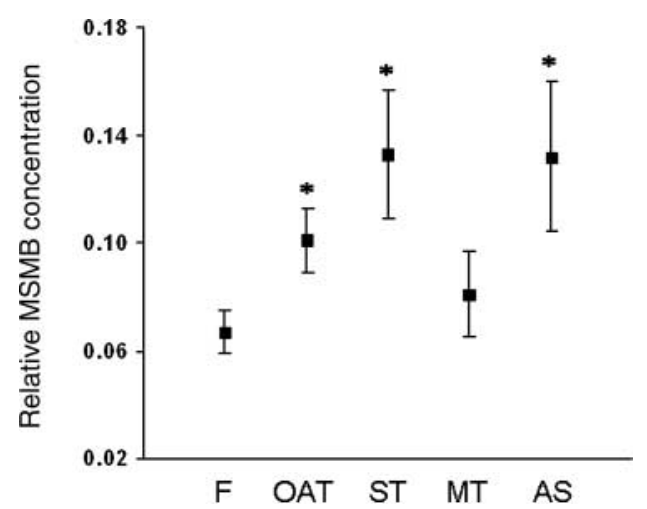

Figure 6 Relative MSMB levels in seminal plasma from different subgroups of men according to their semen parameters. MSMB concentration was expressed relative to the total seminal plasma protein concentration. The squares in the plots represent mean \pm S.E.M. in each group. ${ }^{*} P<0.02$ versus fertile group.

Although MSMB is present in human SP in a relatively high concentration, the relationship of this protein and sperm function is not known to date.

Rabbit polyclonal antibodies generated against pure MSMB were used to investigate the protein localization in fresh human spermatozoa. Most sperm cells showed immunofluorescent staining on the anterior region of the head and neck. Evidence about specific interaction between accessory sex gland proteins and lipid components on the sperm surface has been presented (Muller et al. 1998). This type of interaction usually requires positively charged amino acids as predominant in the protein structure; the MSMB pl $(\mathrm{pl}=5.6)$, however, does not follow this structure. Previous studies on pig MSMB that shares $51 \%$ identity sequence with the human protein has shown a compact structure and rapid evolution. These results led the authors to conclude that direct hydrophobic interaction with the membrane is unlikely to occur suggesting that MSMB might be a peripheral protein that binds to membrane integral proteins (Wang et al. 2005).

On the other hand, pig MSMB decreases $\mathrm{Na}^{+}-\mathrm{K}^{+}-$ ATPase activity and sperm motility (Jeng et al. 1993, Chao et al. 1996) supporting the hypothesis that MSMB belongs to a member of peripheral membrane proteins that can interact with integral proteins. From the sitespecific MSMB localization on the sperm membrane observed by immunofluorescence and electron microscopy in our study, and in accordance with the suggestion of a previous publication (Wang et al. 2005), we speculate that an integral protein on the sperm plasma membrane may act as MSMB receptor.

In a search with FASTA software using the consensus sequence in mammals to look for similar sequences, MSMB exon 3 was recognized by several proteins, one of these being zonadhesin ('zona pellucida-binding protein'). Zonadhesin is secreted by seminal vesicles and prostate, and associates peripherally to the anterior region of the sperm head during ejaculation. This protein prevents the spontaneous AR and participates in gamete recognition by binding the zona pellucida in a speciesspecific manner (Topfer-Petersen et al. 1998). In a recent publication by van Gestel et al., highly purified protein isolated from the apical plasma membrane of the sperm head was used in a direct binding assay with purified ZP ghosts. The authors concluded that multiple proteins are involved in primary sperm-zona interactions (Van Gestel et al. 2007). Like MSMB, some of these proteins (AQN-3 and $\mathrm{P} 47$ ) are peripherally associated to the sperm and located at the plasma membrane covering the acrosome. In addition, the authors were not able to identify all of the proteins implicated, supporting the possible involvement of MSMB in the sperm-ZP interaction.

Recently, published results showed MSMB (PSP94) immunolocalization on macaque sperm and revealed that this protein and the $\beta$-defensin ESP13.2 constituted $\sim 95 \%$ of the proteins released from the sperm surface during capacitation (Tollner et al. 2004). In macaque, MSMB resides on the sperm up to the final stages of capacitation and appears to be localized to the flagellum. Sperm treated with caffein or dbcAMP retained MSMB over the tail, and they did not develop hyperactivated movement characteristics associated with capacitation. A role for MSMB in regulating hyperactivated motility remains a possibility.

Although there is a relatively high identity between rhesus monkey and human protein primary sequences, many of the amino acid replacements affect charged residues that lead to major changes in isolectric points. We believe that this could be one of the explanations for the difference of the MSMB localization, and may be in the function, observed between the two species.

It has been reported that MSMB is bound to CRISP3 in human SP in a high-affinity complex through the $\mathrm{N}$-terminal 'sperm coating protein' (SCP) domain. Even CRISP3 function is not known, the carboxyl-terminus end of the protein shows similarity with potassium channel inhibitors (Guo et al. 2005). In addition, it has been suggested that MSMB is likely to bind other proteins with an SCP domain (Roberts et al. 2003, Udby et al. 2005), i.e., CRISP1, which in rats was shown to inhibit sperm capacitation and thus prevent premature sperm activation (Roberts et al. 2003). Together, these data suggest that MSMB may have a role as modulator of sperm physiology.

Since MSMB has specific binding sites on the sperm surface, we examined an animal model to evaluate MSMB effect on epididymal spermatozoa preincubated with exogenously added protein. We found that MSMB binds to the acrosomal region of guinea pig spermatozoa, interestingly the same localization observed in human sperm. Based on this observation, we evaluated the effect of MSMB, in a physiologic concentration, on the spontaneous AR of guinea pig epididymal sperm. Our results indicated that the presence of MSMB in the 
incubation medium caused a statistically significant inhibition of the AR. Although extrapolation of these results to human sperm may or not be valid, these data suggest that MSMB could prevent the occurrence of a premature AR previous to sperm-egg interaction at the fertilization site. On the other hand, we speculate that MSMB could be lost from the human sperm head after the acrosomal reaction, but whether or not this occurs is a matter for future investigation.

In recent years, several reports have attempted to correlate different SP protein levels and semen parameters, such as sperm concentration, motility, and morphology (Baumgart et al. 2002, Zhang et al. 2002). We followed this objective in order to determine the possible diagnostic validity of MSMB concentration as a biochemical marker that could provide useful information on male fertility potential.

Two monospecific antibodies were generated using MSMB purified from human SP. Using these antibodies, we developed a double-site ELISA to evaluate MSMB concentration in human SP of individuals with different semen parameters.

Seminal plasma MSMB levels from OAT, AS, ST, MT, and fertile donors were measured. We found that the MSMB mean values of OAT, AS, and ST groups were significantly higher than in the fertile group. We believe that this could be due to either a decreased prostate synthesis or secretion, or on the other hand, it could be attributed to a diminution in the number of MSMB molecules bound to the spermatozoa. In support of the latter hypothesis, the pathologic groups with MSMB levels above the fertile group shared the characteristics of low percentage of morphologically normal spermatozoa and low motility. The differences observed between groups could relate to defects at the molecular level, which are reflected macroscopically on the cellular morphology. These data provide some evidence of the association of MSMB with semen quality, and suggest that this protein should continue to be investigated as a possible biomarker of semen quality. It could be interesting to determine MSMB concentration in sperm protein extracts and its association with sperm morphology and other seminal parameters.

In summary, we have reported for the first time MSMB binding to the human sperm surface as well as the relative MSMB concentration in human SP from different subgroups of individuals according to their sperm parameters. A significant higher concentration was found in some of the subfertile groups of patients showing sperm deficiencies when compared with the fertile group. In addition, MSMB bound to the acrosomal region of guinea pig epididymal sperm, reduced their ability to undergo spontaneous AR. The physiological role of this protein and its association with fertility remains to be elucidated.

\section{Materials and Methods}

\section{Subjects and semen samples}

The study was approved by the Bioethics Committee of the Medical School, Cordoba National University. All subjects signed an informed consent. Semen samples were obtained from subjects who presented to the Andrology and Reproduction Laboratory (LAR) at Cordoba, Argentina. Collection, analysis, and classification of the ejaculates were performed according to World Health Organization recommendations (WHO 1999). Briefly, the samples were obtained by masturbation into a sterile plastic tube after 3-5 days of abstinence. Following physical examination of the ejaculate $(\mathrm{pH}$, volume, semen characteristics, sperm viability, concentration, motility, and morphology), the samples were centrifuged at $3000 \mathrm{~g}$ and the SP was stored at $-80{ }^{\circ} \mathrm{C}$ until analyzed. Sperm morphology was examined by strict criteria (Kruger et al. 1986, Menkveld et al. 1990, WHO 1999) and expressed as \% normal forms. Semen samples having $>1 \times 10^{6}$ leukocytes $/ \mathrm{ml}$ were excluded. The samples were coded so that the donor remained anonymous and blinded to the authors of this study.

Semen samples were obtained from 62 patients consulting for infertility: 38 OAT, 7 AS, 8 ST, and 9 MT; and from 6 fertile donor (F) men. The fertile men were in overall good health, had fathered a pregnancy within the last 2 years and had normal semen parameters. Teratozoospermia was classified as severe ( $\leq 4 \%$ normal forms) or moderate (5-10\% normal forms) following previous reports (Oehninger 2001). In all cases, except for the fertile group, two samples were analyzed in a 7 to 21-day period, according to the $\mathrm{WHO}$ recommendations (WHO 1999), to arrive at the diagnosis.

\section{Animals}

Male adults guinea pigs (body weight $\sim 700 \mathrm{~g}$ ) were housed in air-conditioned rooms under a photoperiod of $14 \mathrm{~h}$ light: $10 \mathrm{~h}$ darkness. Food (commercial diet) and water were available ad libitum. Animals were killed with carbon dioxide gas and epididymal sperm were obtained from the caudal region of the epididymis as described previously (Coronel \& Lardy 1992). All experimental protocols were conducted in accordance with the NIH Guide for the Care and Use of Laboratory Animals.

\section{Protein purification}

Pooled semen samples from healthy donors were centrifuged $17000 \mathrm{~g}$ at $2{ }^{\circ} \mathrm{C}$ for $30 \mathrm{~min}$. Each supernatant was dialyzed against $8 \mathrm{I}$ of $25 \mathrm{mM}$ Tris- $\mathrm{HCl}(\mathrm{pH}$ 7.6) buffer supplemented with protease inhibitors and brought to $35 \%$ saturation with solid ammonium sulfate, stirred for $30 \mathrm{~min}$, and allowed to stand at $0{ }^{\circ} \mathrm{C}$ for $1 \mathrm{~h}$. The sample was centrifuged again, the supernatant was brought to $70 \%$ saturation and left overnight at $4{ }^{\circ} \mathrm{C}$ and then centrifuged as above. The pellet was dissolved in minimum volume of $25 \mathrm{mM}$ Tris- $\mathrm{HCl}(\mathrm{pH}$ 7.6) and dialyzed overnight against $8 \mathrm{I}$ of the same buffer. The sample was loaded onto a column $(1.5 \times 140 \mathrm{~cm})$ of Sephadex G-50 superfine (Pharmacia LKB Biotechnology, Uppsala, Sweden) equilibrated 
with $25 \mathrm{mM}$ Tris- $\mathrm{HCl}$ (pH 7.6) buffer. The elution was performed with the equilibration buffer at a rate of $0.50 \mathrm{~cm} / \mathrm{h}$ at room temperature. Since MSMB was first detected in human SP by cross-reaction with an anti-caltrin antibody (Franchi \& Coronel 2001), we used this antibody to select the fractions containing MSMB after each step of the purification procedure. The fractions containing MSMB protein were pooled and submitted to a second cycle of gel filtration in the same conditions as in the first step. The fractions containing MSMB protein were pooled and loaded immediately onto a DEAE Econo-Pac Q Cartridge column equilibrated with the abovementioned buffer. The elution was carried out applying a continuous $\mathrm{NaCl}$ gradient from 0 to $0.5 \mathrm{M}$ in equilibration buffer. The fractions with MSMB were pooled and subjected to an HPLC procedure in an Ultraspherogel Sec 2000 column $(0.75 \times 30 \mathrm{~cm})$. The proteins were detected by recording the absorbance at $280 \mathrm{~nm}$. The purity of isolated protein was assessed by SDS-PAGE.

\section{Protein concentration}

Protein concentration was estimated with bicinchoninic acid following the procedure described by Smith et al. (1985). BSA fraction $\mathrm{V}$ was used as the standard protein.

\section{SDS-PAGE and Western blotting}

Electrophoresis was performed using the Mini-Protean II System (Bio-Rad Laboratories). According to the procedures reported by Laemmli (1970), the stacking and running gel were 7.5 and $15 \%$ acrylamide respectively. The proteins separated by SDS-PAGE were transferred to nitrocellulose membranes by electro-transference using a Trans Blot Cell (Bio-Rad) according to the method of Towbin et al. (1979) as described previously (Winnica et al. 2000). Membranes used for immunodetection of MSMB protein were incubated with the corresponding antiserum. A goat anti-rabbit IgG conjugated with alkaline phosphatase (AP) was used as the secondary antibody. Bound conjugates were visualized by staining for enzymatic activity with 5-bromo-4-chloro-3-indolyl phosphate $p$-toluidine salt and nitroblue tetrazolium (NBT).

\section{Sequencing}

Proteins purified by HPLC $(0.75 \times 30 \mathrm{~cm}$, Ultraspherogel Sec 2000) were sequenced at the Medical College of Wisconsin as described previously (Coronel et al. 1992). Both the gas-phase and pulse liquid-phase sequencers with on-line HPLC for phenylthiohydantoin analysis and the data system were from Applied Biosystems (Foster City, CA, USA). Thirty-five amino acids from the $\mathrm{N}$-terminal were sequenced. To identify the protein, the sequence obtained (SCYFIPNEGVPGDSTRKCMDLKGNKHPINSEWQTD) was analyzed using the publicly available Basic Local Alignment Search Tool (BLAST, http://www.ncbi.nlm.nih.gov/blast). The sequence showed $100 \%$ identity with the precursor of MSMB, isoform a (NP_002434.1). This result was confirmed by the sequencing of a second sample, which gave an identical result.

\section{Antibodies production and purification}

Monospecific polyclonal antibodies were prepared by injecting purified protein into adult male rabbits and adult rats as described previously (Coronel et al. 1988). Approximately, 0.1-0.2 mg MSMB protein in Freund's complete adjuvant $(1: 1$ ratio) was injected via s.c. tissue into adult rabbits and rats. Four weeks later, a second injection of $0.1-0.2 \mathrm{mg}$ MSMB in Freund's incomplete adjuvant was administrated. The antisera titers reached satisfactory levels 2-4 weeks after the second injection, and blood was collected from the animals at that time. The antisera were decomplemented by heating at $60{ }^{\circ} \mathrm{C}$ for $30 \mathrm{~min}$ and then stored frozen in aliquots at $-20^{\circ} \mathrm{C}$. The specificity and titers of the antisera were tested by Western blotting, using 1-3 $\mu$ g pure MSMB.

A fraction of rabbit MSMB antiserum was purified by affinity chromatography in a protein A-Sepharose (Pharmacia LKB Biotechnology) column equilibrated with PBS containing $150 \mathrm{mM} \mathrm{NaCl}$ and $10 \mathrm{mM}$ phosphate buffer at $\mathrm{pH}$ 7.4. The antiserum was eluted with $0.1 \mathrm{M}$ glycine- $\mathrm{HCl}$ buffer at $\mathrm{pH} 2.0$ (Ey et al. 1978). Collected IgG fractions were immediately neutralized with $2 \mathrm{M}$ Tris- $\mathrm{HCl}$ buffer $(\mathrm{pH} 7.5)$. Purified rabbit IgG were designated ca-MSMB (coat antiMSMB) and stored in small aliquots at $-20{ }^{\circ} \mathrm{C}$ until used in ELISA assay. The rat anti-MSMB antiserum will be referred to as da-MSMB (detector anti-MSMB).

\section{Indirect immunofluoresence}

Fluorescence experiments were performed according to the method of Irwin et al. (1983) as described previously for guinea pig spermatozoa (Coronel \& Lardy 1992) using monospecific polyclonal antibodies against MSMB protein prepared in rabbits, as described above using fluorescein isothiocyanate (FITC)-labeled goat anti-rabbit IgG (Sigma). Ejaculated and washed spermatozoa from normozoospermic donors were fixed with $4 \%$ formaldehyde in PBS at $\mathrm{pH}$ 7.4. After washing twice with PBS, the cell suspensions were spread on acetonecleaned glass slides to dry. Dried smears were treated with $3 \%$ normal goat serum for $1 \mathrm{~h}$. The slides were washed with PBS and then covered with 1:1000 MSMB antiserum. After $1 \mathrm{~h}$, the slides were washed with PBS and then treated for 30 min with goat anti-rabbit IgG labeled with FITC diluted 1:100 in PBS. All incubations were performed at room temperature (RT). The preparations were washed with PBS for $1 \mathrm{~h}$ and then covered with a drop of FluorSave Reagent (Calbiochem), and a cover slip was fixed in place. Controls were performed using rabbit nonimmune serum or avoiding first antibody incubation. The preparations were observed in a fluorescence microscope (MicroStar V, Leica, Buffalo, NY, USA).

Epididymal sperm were obtained from the caudal region of guinea pig epididymis in $0.9 \% \mathrm{NaCl}$. Cells were immediately washed and resuspended in modified minimal culture medium (MCM-PL) containing: $110 \mathrm{mM} \mathrm{NaCl}, 20 \mathrm{mM}$ sodium lactate, $1.25 \mathrm{mM}$ sodium piruvato, and $25 \mathrm{mM} \mathrm{NaHCO}_{3}$ at $\mathrm{pH} 7.8$ (Coronel \& Lardy 1987). The cells were incubated for $60 \mathrm{~min}$ in the presence of $0.5 \mathrm{mg} / \mathrm{ml} \mathrm{MSMB}$ at $37{ }^{\circ} \mathrm{C}$ in $95: 5$ air: $\mathrm{CO}_{2}$ and fixed for $20 \mathrm{~min}$ in $4 \%$ formaldehyde. Localization of MSMB was evaluated by IIF according to the protocol used for human 
spermatozoa described previously. Controls included sperm incubation with comparable concentrations of an irrelevant protein (BSA) or avoiding anti-MSMB incubation, and all were negative.

\section{Ultrastructural immunocytochemistry}

Ejaculated spermatozoa were washed with PBS and then resuspended in a blocking solution containing $1 \%$ normal goat serum in PBS and incubated for $15 \mathrm{~min}$ at RT. The blocking solution was discarded, and the cells were incubated overnight at $4{ }^{\circ} \mathrm{C}$ with rabbit anti-MSMB antibody diluted $1: 1000$ or in preimmune rabbit serum (at the same dilution) for control purposes. After washing, bound antibodies were detected with the protein A-colloidal complex (1:10 dilution) for $30 \mathrm{~min}$ at RT. Following three washes, the cells were fixed with $1 \%$ glutaraldehyde in $0.1 \mathrm{mM}$ cacodylate buffer at $\mathrm{pH} 7.4$ for $1 \mathrm{~h}$ and postfixed for $1 \mathrm{~h}$ with $1 \%$ osmium tetroxide in the same buffer. The samples were dehydrated in a series of graded acetones and embedded in Araldite (Electron Microscopy Sciences, Fort Washington, PA, USA). Thin sections cut in a Porter-Blum MT2 ultramicrotome (Sorvall Inc., Newtown, CT, USA) were studied under a Siemens Elmiskop 101 electron microscope.

\section{Gold-complex preparation}

Colloidal gold particles (average diameter, $16 \mathrm{~nm}$ ) were prepared according to a previously published method reducing $0.01 \%$ tetrachloroauric acid solution ( $\mathrm{HauCl} 4$, Merck) with $1 \%$ sodium citrate (Frens 1973). Approximately, $4 \mu \mathrm{g}$ protein A (Sigma) were used to stabilize $1 \mathrm{ml}$ colloidal gold adjusted to $\mathrm{pH} 7.0$ with $0.2 \mathrm{M}$ potassium carbonate. The unbound proteinA was discarded by centrifugation at $60000 \mathrm{~g}$ for $2 \mathrm{~h}$ and the pellet resuspended in PBS containing $0.01 \%(\mathrm{w} / \mathrm{v})$ polyethylene glycol.

\section{Evaluation of acrosomal status on guinea pig spermatozoa}

Epididymal sperm were obtained from the caudal region of guinea pig epididymis as previously described and resuspended in MCM-PL supplemented with $2 \mathrm{mM} \mathrm{CaCl}_{2}$ necessary to allow the AR to occur (Coronel \& Lardy 1987). In order to evaluate MSMB effect on the spontaneous acrosomal reaction, the cells were fixed in $4 \%$ formaldehyde immediately after the $\mathrm{NaCl}$ wash $\left(t_{\mathrm{o}}\right)$ or after different incubation times, at $37{ }^{\circ} \mathrm{C}$ in 95:5 air: $\mathrm{CO}_{2}$, in the absence (control) or presence of $0.5 \mathrm{mg} / \mathrm{ml}$ MSMB. Optimal MSMB concentration was determined in previous experiments. The MSMB effect on the AR was evaluated by direct observation under $1000 \times$ oil immersion in phase contrast microscope counting the number of acrosome-reacted sperm over a total of 200 cells.

\section{MSMB ELISA}

The quantification of MSMB was performed using a two-site binding ELISA specially developed for this study. A combination of two polyclonal anti-MSMB antibodies was employed. ca-MSMB was used to coat polystyrene microtiter plate surface enabling to secure free antigen, and da-MSMB was the detector antibody used to recognize the captured antigen. All measurements were performed in triplicate. Briefly, $50 \mu \mathrm{l}$ ca-MSMB (1:1000) antibody solution were added to the microtiter plate. After overnight incubation at $4{ }^{\circ} \mathrm{C}$, nonspecific binding sites were blocked by incubation with $0.05 \%$ Tween 20-1\% BSA-PBS for $60 \mathrm{~min}$ at RT. Subsequent incubations were carried out sequentially for $30 \mathrm{~min}$ at RT, followed by washings in $0.05 \%$ Tween-20 PBS between each step. Fifty microliters of SP in three different dilutions were placed into microwell. Incubation with da-MSMB antibody (1:1000) was followed by addition of mouse anti-rat (1:1000) conjugated to alkaline phosphatase (AP). All dilutions were carried out in blocked solution. Bound phosphatase was visualized by incubation in $1 \mathrm{mg} / \mathrm{ml}$-nitrophenyl phosphate ( $\mathrm{p}-\mathrm{NPN}$ ) in $1 \mathrm{M}$ diethylamine buffer $(\mathrm{pH}$ 9.8) containing $0.02 \mathrm{M}$ of sodium azide at RT for $20 \mathrm{~min}$. The reaction was terminated by the addition of $11 \mu \mathrm{l}$ of $2 \mathrm{M} \mathrm{NaOH}$, and the absorbance of the colored substance produced was measured at $405 \mathrm{~nm}$ using an ELISA reader (ICNTitertek Multiskan MCC/340). The sandwich-ELISA yielded satisfactory results when rabbit normal serum was preincubated with phosphatase-conjugated goat anti-rat-IgG. This immunoassay was employed to measure MSMB in human SP at an appropriate dilution. The dilutions of SP samples were selected from three values so that the measured MSMB level was within the range. To calculate the MSMB concentration, the absorbances were compared with the values of the calibration curve using pure MSMB. MSMB concentration was expressed as $\mathrm{mg} / \mathrm{ml}$ of SP and also relative to $\mathrm{SP}$ total protein concentration $(\mathrm{mg} / \mathrm{ml})$. The within-assay and between-assay coefficient of variations were 7.21 and $15.05 \%$ respectively.

\section{Statistical analysis}

Results are expressed as mean \pm S.D. or S.E.M. as indicated in the figure legends. Statistical significance was determined using Student's $t$-test or two-way ANOVA analysis. $P \leq 0.05$ was considered statistically significant.

\section{Declaration of interest}

The authors declare that there is no conflict of interest that would prejudice the impartiality of this scientific work.

\section{Funding}

This work was supported by grants from Consejo Nacional de Investigaciones Científicas y Técnicas (CONICET) and Secretaria de Ciencias y Tecnología de la Universidad Nacional de Córdoba to C E C, and a grant from Programa Latinoamericano de Capacitación e Investigación en Reproducción Humana (PLACIRH) to N A F. C E C is a career scientist of CONICET. 


\section{References}

Akiyama K, Yoshioka Y, Schmid K, Offner GD, Troxler RF, Tsuda R \& Hara M 1985 The amino acid sequence of human beta-microseminoprotein. Biochimica et Biophysica Acta 829 288-294.

Amann RP 1989 Can the fertility potential of a seminal sample be predicted accurately? Journal of Andrology 10 89-98.

Baumgart E, Lenk SV, Loening SA \& Jung K 2002 Quantitative differences in matrix metalloproteinase (MMP)-2, but not in MMP-9, tissue inhibitor of metalloproteinase (TIMP)-1 or TIMP-2, in seminal plasma of normozoospermic and azoospermic patients. Human Reproduction 17 2919-2923.

Chao CF, Chiou ST, Jeng H \& Chang WC 1996 The porcine sperm motility inhibitor is identical to beta-microseminoprotein and is a competitive inhibitor of $\mathrm{Na}+, \mathrm{K}(+)$-ATPase. Biochemical and Biophysical Research Communications 218 623-628.

Coetzee K, Kruger TF, Lombard CJ, Shaughnessy D, Oehninger S, Ozgur K, Pomeroy KO \& Muller CH 1999 Assessment of interlaboratory and intralaboratory sperm morphology readings with the use of a Hamilton Thorne Research integrated visual optical system semen analyzer. Fertility and Sterility 71 80-84.

Coronel CE \& Lardy HA 1987 Characterization of $\mathrm{Ca}^{2+}$ uptake by guinea pig epididymal spermatozoa. Biology of Reproduction 37 1097-1107.

Coronel CE \& Lardy HA 1992 Functional properties of caltrin proteins from seminal vesicle of the guinea pig. Molecular Reproduction and Development 33 74-80.

Coronel CE, San Agustin J \& Lardy HA 1988 Identification and partial characterization of caltrin-like proteins in the reproductive tract of the guinea pig. Biology of Reproduction 38 713-722.

Coronel CE, Winnica DE, Novella ML \& Lardy HA 1992 Purification, structure, and characterization of caltrin proteins from seminal vesicle of the rat and mouse. Journal of Biological Chemistry 267 20909-20915.

Douglas-Hamilton DH 1995 Validation procedures for the Hamilton Thorne Integrated Visual Optical System sperm and cell analyzer. Quality Assurance 4 340-347.

Ey PL, Prowse SJ \& Jenkin CR 1978 Isolation of pure IgG1, IgG2a, IgG2b immunoglobulins from mouse serum using protein A-Sepharose. Biochemistry 15 429-436.

Fernlund P, Granberg LB \& Roepstorff P 1994 Amino acid sequence of beta-microseminoprotein from porcine seminal plasma. Archives of Biochemistry and Biophysics 309 70-76.

Fernlund P, Granberg LB \& Larsson I 1996 Cloning of beta-microseminoprotein of the rat: a rapidly evolving mucosal surface protein. Archives of Biochemistry and Biophysics 334 73-82.

Franchi A \& Coronel CE 2001 Caltrin-like proteins from human seminal plasma. Purification and sequence of a 15 kDa molecule. Biocell 25302.

Frens G 1973 Controlled nucleation for the regulation of the particule size in monodisperse gold solutions. Nature 241 20-22.

Van Gestel RA, Brewis IA, Ashton PR, Brouwers JF \& Gadella BM 2007 Multiple proteins present in purified porcine sperm apical plasma membranes interact with the zona pellucida of the oocyte. Molecular Human Reproduction 13 445-454.

Guo M, Teng M, Niu L, Liu Q, Huang Q \& Hao Q 2005 Crystal structure of cystein-rich secretory protein stecrisp reveals the cystein-rich domain has $\mathrm{a} \mathrm{K}^{+}$-channel inhibitor-like fold. Journal of Biological Chemistry $\mathbf{2 8 0}$ 12405-12412.

Guzick DS, Overstreet JW, Factor-Litvak P, Brazil CK, Nakajima ST, Coutifaris C, Carson SA, Cisneros P, Steinkampf MP, Hill JA et al. 2001 Sperm morphology, motility, and concentration in fertile and infertile men. New England Journal of Medicine 345 1388-1393.

Henkel R 2007 Detection of DNA damage in sperm. In Male Infertility. Diagnosis and Treatment, pp 225-238. Eds SC Oehninger \& TF Kruger. Informa Healthcare, London, UK.

Irwin M, Nicholson N, Haywood JT \& Poirier GR 1983 Immunofluorescent localization of a murine seminal vesicle proteinase inhibitor. Biology of Reproduction 28 1201-1206.

Jeng H, Liu KM \& Chang WC 1993 Purification and characterization of reversible sperm motility inhibitors from porcine seminal plasma. Biochemical and Biophysical Research Communications 191 435-440.

Jorgensen N, Auger J, Giwercman A, Irvine DS, Jensen TK, Jouannet P, Keiding N, Le Bon C, Macdonald E, Pekuri AM et al. 1997 Semen analysis performed by different laboratory teams: an intervariation study. International Journal of Andrology 20 201-208.
Kamada M, Mori H, Maeda N, Yamamoto S, Kunimi K, Takikawa M, Maegawa M, Aono T, Futaki S \& Koide SS 1998 B-Microseminoprotein/ prostatic secretory protein is a member of immunoglobulin binding factor family. Biochimica et Biophysica Acta 1388 101-110.

Krause W 1995 Computer-assisted semen analysis systems: comparison with routine evaluation and prognostic value in male fertility and assisted reproduction. Human Reproduction 10 (Supplement 1) 60-66.

Kruger TF, Menkveld R, Stander FS, Lombard CJ, Van Der Merwe JP, Van Zyl JA \& Smith K 1986 Sperm morphologic features as a prognostic factor in in vitro fertilization. Fertility and Sterility $\mathbf{4 6}$ $1118-1123$.

Kwong J, Xuan JW, Chan PS, Ho SM \& Chan FL 2000 A comparative study of hormonal regulation of three secretory proteins (prostatic secretory protein-PSP94, probasin, and seminal vesicle secretion II) in rat lateral prostate. Endocrinology 141 4543-4551.

Laemmli UK 1970 Cleavage of structural proteins during the assembly of the head of bacteriophage T4. Nature 227 680-685.

Menkveld R, Stander FS, Kotze TJ, Kruger TF \& Van Zyl JA 1990 The evaluation of morphological characteristics of human spermatozoa according to stricter criteria. Human Reproduction 5 586-592.

Muller P, Erlemann KR, Muller K, Calvete JJ, Topfer-Petersen E, Marienfeld K \& Herrmann A 1998 Biophysical characterization of the interaction of bovine seminal plasma protein PDC-109 with phospholipid vesicles. European Biophysics Journal 27 33-41.

Neuwinger J, Behre HM \& Nieschlag E 1990 External quality control in the andrology laboratory: an experimental multicenter trial. Fertility and Sterility 54 308-314.

Nikolettos N, Kupker W, Demirel C, Schopper B, Blasig C, Sturn R, Felberbaum R, Bauer O, Diedrich K \& Al-Hasani S 1999 Fertilization potential of spermatozoa with abnormal morfology. Human Reproduction 14 47-70.

Nolet S, St-Louis D, Mbikay M \& Chretien M 1991 Rapid evolution of prostatic protein PSP94 suggested by sequence divergence between rhesus monkey and human cDNAs. Genomics 9 775-777.

Ochiai Y, Inazawa J, Ueyama H \& Ohkubo I 1995 Human gene for $\beta$-microseminoprotein: its promoter structure and chromosomal localization. Journal of Biochemistry 117 346-352.

Oehninger S 2001 Place of intracytoplasmic sperm injection in management of male infertility. Lancet 357 2068-2069.

Roberts KP, Wamstad JA, Ensrud KM \& Hamilton DW 2003 Inhibition of capacitation-associated tyrosine phosphorylation signaling in rat sperm by epididymal protein Crisp-1. Biology of Reproduction 69 572-581.

Sakai H, Tsurusaki T, Kanda S, Koji T, Xuan JW \& Saito Y 1999 Prognostic significance of beta-microseminoprotein mRNA expression in prostate cancer. Prostate 38 278-284.

Smith PK, Krohn RI, Hermanson GT, Mallia AK, Gartner FH, Provenzano MD, Fujimoto EK, Goeke NM, Olson BJ \& Klenk DC 1985 Measurement of protein using bicinchoninic acid. Analytical Biochemistry 150 76-85.

Tollner TL, Yudin AI, Treece CA, Overstreet JW \& Cherr GN 2004 Macaque sperm release ESP13.2 and PSP94 during capacitation: the absence of ESP13.2 is linked to sperm-zona recognition and binding. Molecular Reproduction and Development 69 325-337.

Topfer-Petersen E, Romero A, Varela PF, Ekhlasi-Hundrieser M, Dostalova Z, Sanz L \& Calvete JJ 1998 Spermadhesins: a new protein family. Facts, hypotheses and perspectives. Andrologia 30 217-224.

Towbin H, Staehelin T \& Gordon J 1979 Electrophoretic transfer of proteins from polyacrylamide gels to nitrocellulose sheets: procedure and some applications. PNAS 76 4350-4354.

Udby L, Lundwall K, Johnsen AH, Fernlund P, Valtonen-Andre C, Blom AM, Lilja H, Borregaard N, Kjeldsen L \& Bjartell A 2005 B-Microseminoprotein binds CRISP-3 in human seminal plasma. Biochemical and Biophysical Research Communications 333 555-561.

Wang I, Lou YC, Wu KP, Wu SH, Chang WC \& Chen C 2005 Novel solution structure of porcine beta-Microseminoprotein. Journal of Molecular Biology 346 1071-1082.

Winnica DE, Novella ML, Dematteis A \& Coronel CE 2000 Trypsin/acrosin inhibitor activity of rat and guinea pig caltrin proteins. Structural and functional studies. Biology of Reproduction 63 42-48. 
World Health Organization 1999 Laboratory manual of the World Health Organization for the examination of human semen and sperm-cervical mucus interaction, Cambridge: Cambridge University Press.

Xuan JW, Wu D, Guo Y, Garde S, Shum DT, Mbikay M, Zhong R \& Chin JL 1997 Molecular cloning and gene expression analysis of PSP94 (prostate secretory protein of 94 amino acids) in primates. DNA and Cell Biology 16 627-638.

Xuan JW, Kwong J, Chan FL, Ricci M, Imasato Y, Sakai H, Fong GH, Panchal C \& Chin JL 1999 cDNA, genomic cloning, and gene expression analysis of mouse PSP94 (prostate secretory protein of 94 amino acids). DNA and Cell Biology 18 11-26.
Zhang Q, Shimoya K, Ohta Y, Chin R, Tenma K, Isaka S, Nakamura H, Koyama M, Azuma C \& Murata Y 2002 Detection of fractalkine in human seminal plasma and its role in infertile patients. Human Reproduction 17 1560-1564.

Received 22 January 2008

First decision 13 February 2008

Revised manuscript received 6 April 2008

Accepted 8 May 2008 